\title{
Design and Implementation of Simulation Training System of Immersion Transformer Substation
}

\author{
ZHOU Zhengjie ${ }^{1, \text { a }}$, LUO Yongsheng ${ }^{2}$ \\ ${ }^{1,2}$ Guangxi Technological College of Machinery and Electricity, Nanning city, Guangxi Prov. China \\ 530007 \\ azzj0502@163.com
}

Keywords: Substation, simulation training system, immersion

\begin{abstract}
Transformer substation operation process should first ensure the running safety. Job skill of substation operation staff is one of the important factors to make sure the safe operation of power system reliability. Therefore, the attendant must pass professional training to mount guard operation. Traditional training methods are taught through the book, on the drawings or analog board practice operation and conducting simulation exercises to foster the operational personnel skills and the ability of dealing with accidents. Although all play a role, due to lacking sense of reality, the training effect is not so good. The traditional way of training is not only high cost, the effect is not ideal, and some faults in the actual occurs only can obtain the actual operation. Substation simulation training system can simulate a similar real substation simulation substation, in this way, training personnel can carry out a series of training skills in this simulation substation operation, patrol, accident rehearsal and etc.
\end{abstract}

\section{The characteristics of substation simulation training}

Substation simulation training system consists of $6 \mathrm{KV}, 35 \mathrm{KV}, 110 \mathrm{KV}, 220 \mathrm{KV}$ and $500 \mathrm{KV}$ v voltage grades, different voltage grade substation mutual connects with each other,. The simulation of each substation is a real substation running right now, and it can be combined closely with the training and the sound field. The software is established in the graphical modeling support on the basis of a substation operation staff training system. It not only makes a comprehensive simulation of the first and second part of the transformer substation. And for the integrated automation part, it also does simulation. The stage of substation is achieved by means of 3-D scene parts. Using the graphical modeling to support the system, which allows the user to program and modify the simulation system.

Students adopt the latest graphics, image processing making image more realistic and operation more simple. Software is mainly divided into three parts: teaching control, the main program, and the students at the scene of the substation. Substation simulation and simulation grid integration design can truly simulate mutual connection and mutual function between the power system grid and substations. Using 3-D graphics technology to build 3-D interactive virtual scene makes the substation training personnel more comprehensive and detailed for study.

Adopting the model of network classroom to train students is supported by a group of faculty and 20 groups of students. There are two computers in each group of faculty and students: one computer displays simulation substation control side, the operation side, the other machine simulates substation site sections with 3-D image, and each group is independent. Teachers can control any student by training system in order to train students to make their own study, and learn under the guidance of teachers. It makes learning way more diversity, and the training effect is obvious.

\section{Structure of the substation simulation training system}

Hardware structure of substation simulation training system mainly has the host server, faculty stand workstations, communication server workstation printers, and network equipment, for hardware structure diagram is shown in chart 1 . Virtual substation simulation system software mainly includes field simulation, computer monitoring system software, simulation support 
software, operating system and system software of trainees and etc, see the chart 2 . The whole simulation training system organically connects with operation management system and database system through interactive simulation software supporting platform.

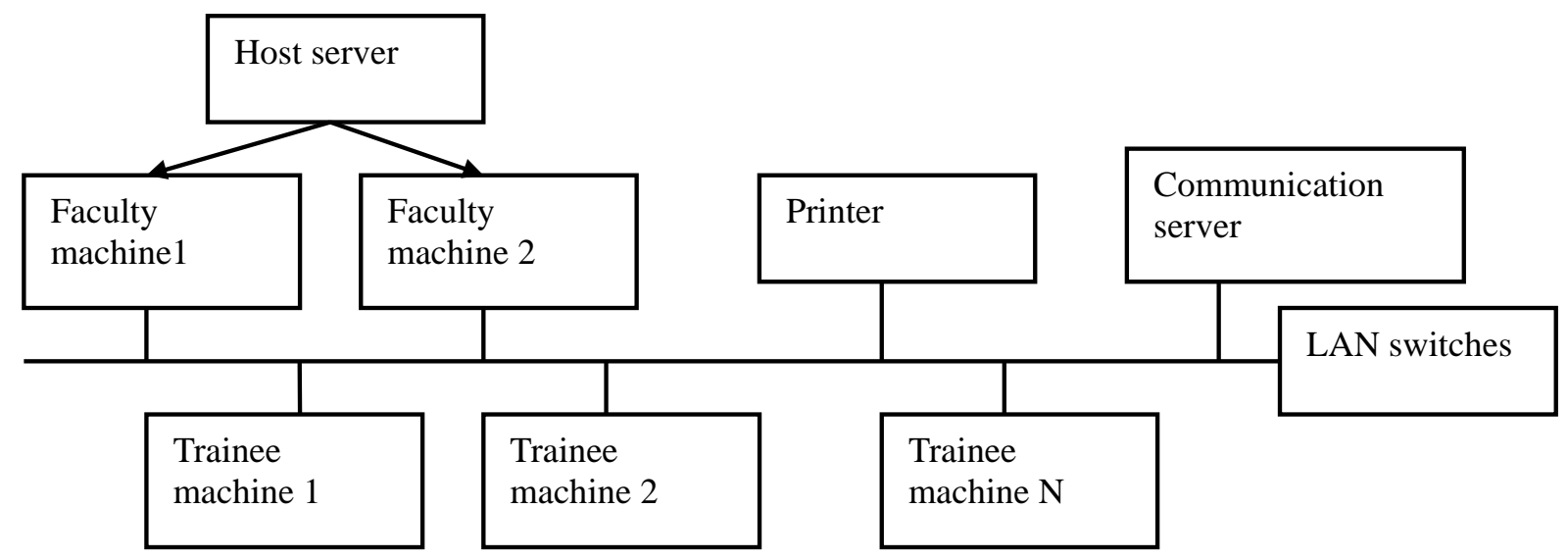

Chart 1: the hardware structure of the substation simulation system

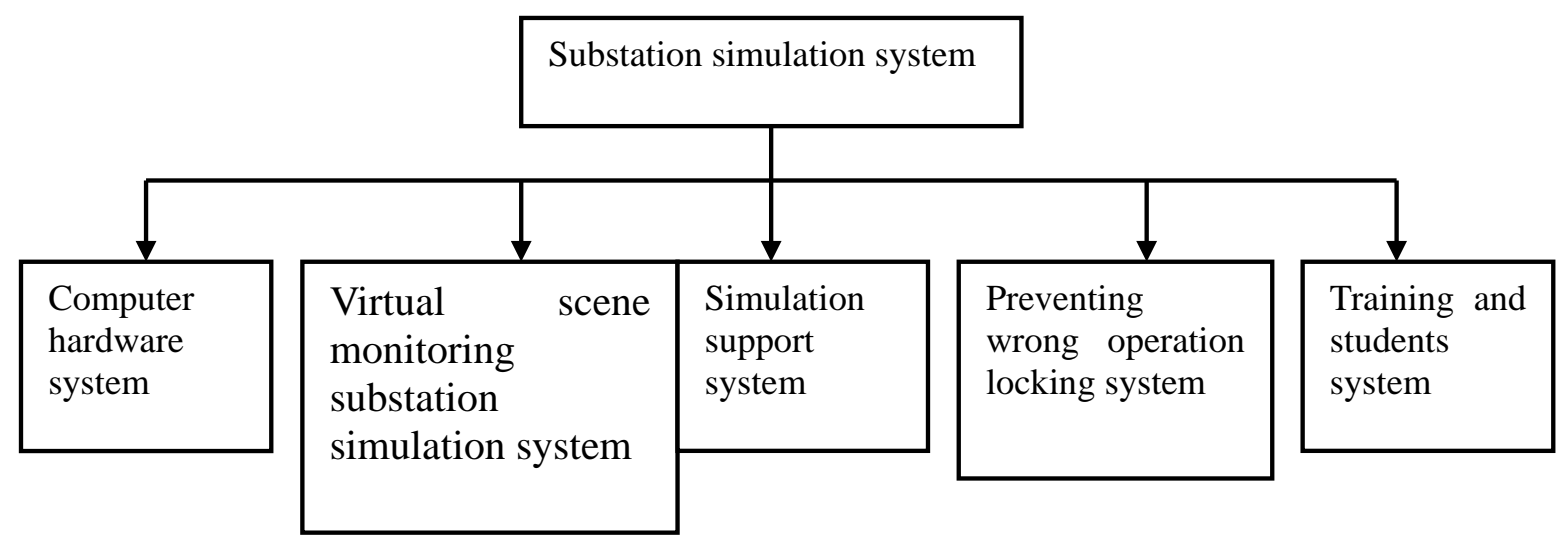

Chart 2: the hardware structure of the substation simulation system

The core part of simulation system is the host server, and it controls workstation,. The workstation consists of two independently operating microcomputer, one station is also the system engineer for system maintenance and upgrade and etc. Faculty machine uses the network to individually control students. Students can be independent in their respective participant's machine operation. The whole system completes the data exchange with external systems through the communication server. Simulation system software consists of the computer software system, virtual scene monitoring substation simulation system, simulation support system software; prevent wrong operation of locking system and the training and students system.

\section{The functions of substation simulation system}

\section{Substation equipment patrol simulation}

Equipment patrol inspection is an important part of the substation running management work. It is to check the running status of equipment in order to grasp the equipment operation rule, to ensure the safe operation of the transformer substation is one of the most important skills necessary. Substation simulation training system with its realistic 3-D images simulates the scene of the substation equipment to wander about in the transformer substation comprehensive testing of the multi-angle comprehensive of patrol. Setting fault on the coach makes students inspect equipment more real in the process of patrol. 


\section{Substation switching operation simulation}

In the process of power system operation, pour the brake operation is a complex and important work, is also one of the most emphasis and difficult in substation operation work, is a key process to confirm the concrete embodiment of substation work, is the assurance of normal operation of power system.

\section{Substation accident handling simulation}

The power system accident refers to all or part of the fault, stability failure and staff work mistakes making the system the normal operation of the damaged, causes stop point, send less to the user's, and power quality deteriorate to the point of can't tolerate, serious when even damage the equipment. As shown in figure 1

$$
\begin{aligned}
& h_{A B}=a 1-b 1=(a-a a 1)-(b-b b 1) \\
& a a 1=\frac{D_{A}^{2}}{2 R}, b b 1=\frac{D_{B}^{2}}{2 R} \\
& \text { So } h_{A B}=(a-a a a 1)-(b-b b 1)=a-b-\frac{D_{A}^{2}-D_{B}^{2}}{2 R} \\
& \text { So } C=\frac{D_{A}^{2}-D_{B}^{2}}{2 R}
\end{aligned}
$$

\section{The design and implementation of the system}

\section{The overall design of the system}

Grid simulation, immersion transformer substation scene simulation, substation operation logic simulation, simulation integrated substation automation system, body feeling capture interaction, faculty management all constitute the software system, each module realizes the simulation process of time synchronization, information interaction and coordinated control through simulation operation support platform, and chart 3 shows the general structure of software system.

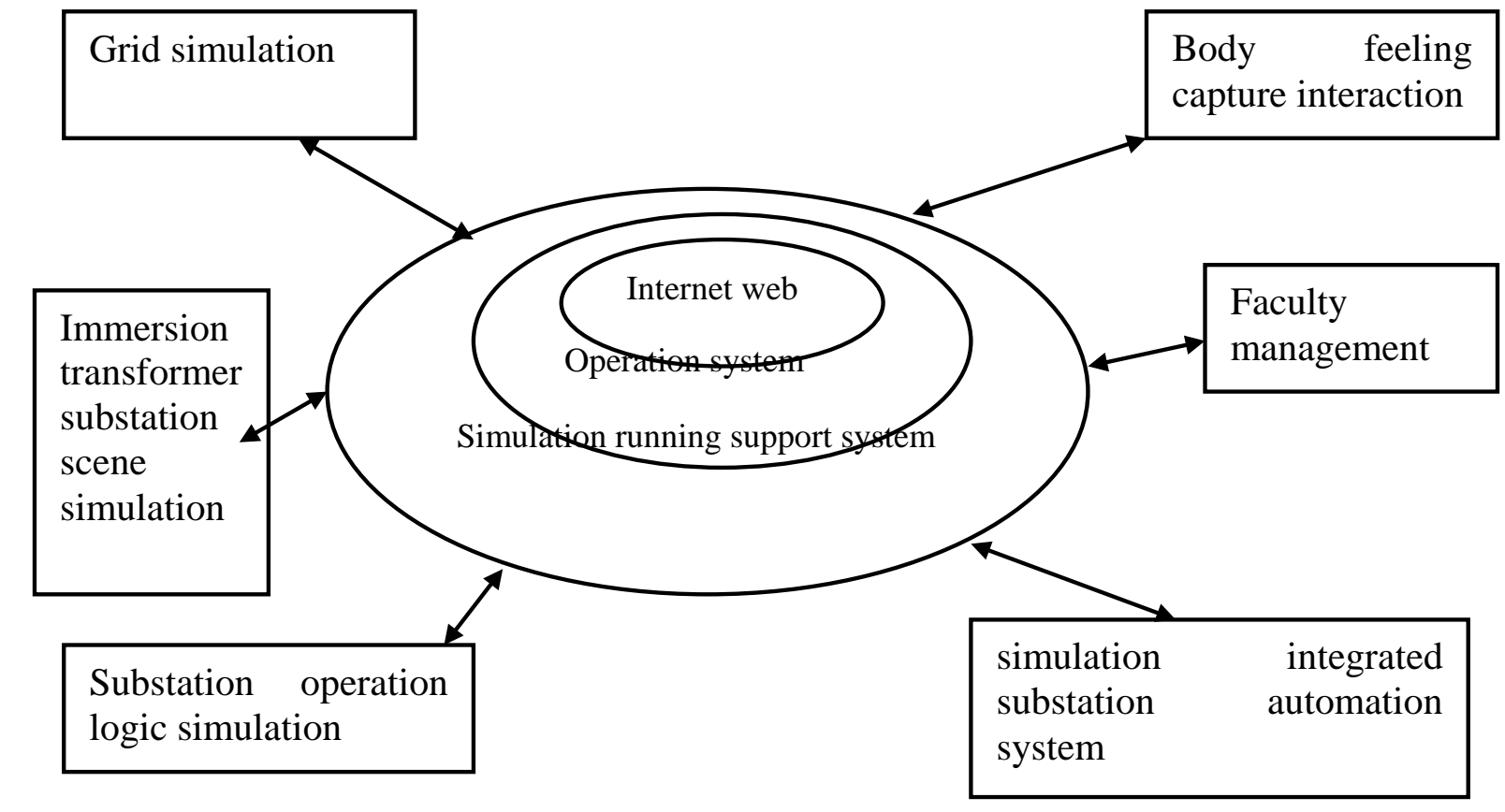

Chart 3: Structure diagram of immersive simulation training system

System hardware system structure of immersion transformer substation simulation training is as shown in chart 4, by the large arc screen 3-D interactive projection, Kinect sensors, workstations and network switches. 


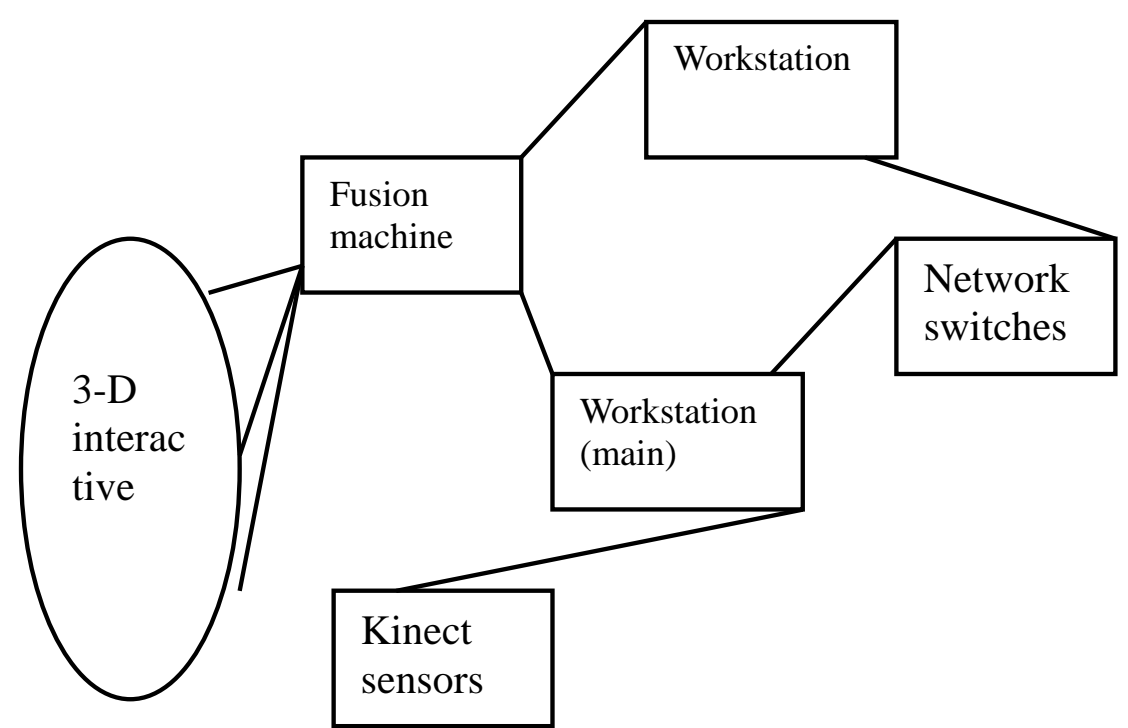

\section{The key skills to implement the system}

Chart 4: Structure diagram of hardware system

\section{1) The multichannel video output technology}

Multi-channel video output technology is the foundation of projection type immersive virtual reality system. This system adopting the multi-channel video output technology is to develop a 3-D conversion between the simulation application program and the computer directX graphics engine interface. When simulation application program uses computer directX graphics engine for drawings, 3-D conversion interface acquires graphic data of simulation software, and copies graphics into graphic data around for 3-D display,

2) Body sense of interactive virtual drive technology based on the Kinect

Kinect body sense of interactive technology accurately capture the student body and local body movements, and location information of six degrees of freedom to capture the real-time tracking. The tracking data is sent via interface software to the immersion transformer substation scene simulation software to complete the realistic simulation operation.

3) Gesture recognition scene roaming technology based on Kinect

Substation simulation training often needs trainees to control virtual people roaming operation in a secondary device. Due to the limitation of access to capture range, virtual roaming can not rely on synchronously driven by human action, so this system uses gesture recognition scene roaming technology based on Kinect, better realizes the virtual roaming and steering control. Trainees can complete virtual characters real-time tracking of students body movements, complete virtual people walking forward, backward, turn left, turn to the right, stand in situ, and other functions.

\section{Summary}

On the basis of the virtual reality, immersion simulation training system adds output stereo images and the device body sense of interactive technology, has solved the defects of the original users of the system lacking a sensed presence and user experience. Compared with the traditional simulation system, it has the characteristics of high real-time and immersive, good system integration and development, as well as the diversity of interaction and etc. It not only makes users feel at the seen, but also can directly interact with virtual environment through body language. Users can feel and respond to a virtual environment through this kind of interactive way, and it makes the participants not be only a mere recipients passive state any more, which can effectively improve the efficiency of power grid to run production staff professional training skills and shorten training cycle and improve the quality of training. 


\section{References}

[1] Zhang Dongying, Yang Yihan, Reviewe of substation simulation training[J]. power system automation,1999,23(23):11-14.

[2] Mingmin Zhang, Zhigeng Pan, Pheng-Ann Heng. Time-critical rendering algorithm with incorporation of LoD, visibility culling and object impostor [J]. the journal of visualization and computer animation (S1049-8907), 2003: 14: 1-13.

[3] Li Jianxin, Chen Yuanyuan, Zhang Zuizhuang, Design of coal mine equipment management information system based on B/S and C/S mixed mode[J]. Hill machinery, 2010(8):37-39.

[4] Gong Qinwu, Jiang Fangfang, Substation simulation training system based on virtual reality technology[J]. Power System source, 2005, 29(24):74-77.

[5] Wang Bangzhi, Lin Channian, Pu Tianjiao, Design and implementation of centralized monitoring substation simulation training system[J]. Power System source, 2004,28(15):21-24. 